\title{
FINANCIAL SECTOR STOCKS REACTION TO COVID-19 EVENTS
}

\author{
Filip Peovski \\ Teaching and Research Assistant at Faculty of Economics - Skopje, Ss. Cyril and Methodius \\ University in Skopje \\ peovski@eccf.ukim.edu.mk \\ Igor Ivanovski \\ Professor at Faculty of Economics - Skopje, Ss. Cyril and Methodius University in Skopje \\ igor.ivanovski@eccf.ukim.edu.mk \\ Sulejman Ahmedi \\ Professor at Faculty of Law, University of Tetovo \\ sulejman.ahmedi@unite.edu.mk
}

\begin{abstract}
Price fluctuations in the financial sector are often of major interest when projecting the general performance and state of the economy. The implications of the COVID-19 pandemic in the sector are analyzed through the event study method. A random sample portfolio of 20 financial sector stocks listed on the NYSE is used and its reaction on 15 different events throughout 2020 is observed. Results indicate that events in the earlier stage of the pandemic exhibit both higher abnormal returns and significance, compared to the ones at the latter stages, with a larger proportion of them being bad news. The financial sector is perceived to react significantly in such cases, usually anticipating them beforehand. As adjustment windows are rarely significant, the market's reaction is deemed as efficient. The general conclusion is that the financial sector stocks react to important COVID-19 news, generating abnormal rather than expected returns.
\end{abstract}

Keywords: COVID-19, Efficient Market Hypothesis, event study, financial sector, stock market.

\section{JEL classification: $G 14$}

\section{INTRODUCTION}

The ongoing COVID-19 pandemic is still the main research focal due to its immense importance in converging to one of the biggest economic crises alongside the health one. Societies and economies have not fully recovered yet, with such tendencies being almost unreachable in present times in the less developed economies. Even though this paper assesses the impact of the pandemic, it observes only its particular and selected financial implications. The presence of higher volatility during the first and the second quarter in 2020 was a worldwide phenomenon, with both low and highly developed financial markets showing signs of it. The study aims to estimate how portfolio returns react to a different type of news and to draw a conclusion whether such reactions abide by the pre-existing theory or not.

While perceived as simple, the event study analysis is an important tool in quantifying the impact of specific news, mostly dealing with higher-frequency data. Quarterly and annual datasets are inadequate for this type of analysis. Many papers use such an approach and their implications deserve to be explored further. The efficient market hypothesis plays a central role in portfolio analysis. Academicians consensually state that its implications depend on the size 
of the market and its development, mostly supporting the manifestation of a semi-strong efficiency. Stock splits, dividend announcements, mergers and acquisitions, policy changes, etc. are commonly present and analyzed within the literature, with the focus gradually shifting on the impact of the COVID-19 pandemic in the past months. This paper deals with the question of whether the pandemic-related news can act as a significant determinant in the return fluctuation of the financial sector portfolio.

For the measurement of the impact, a random sample portfolio of 20 stocks of companies with a market capitalization in the range between $\$ 300 \mathrm{M}$ and over $\$ 200 \mathrm{~B}$ is observed. A cumulative window of daily returns throughout 2016-2020 is used, with the first four years used as an estimation period. In 2020 we concentrate on the event windows upon which we conduct the research. Each of the portfolio stocks is listed at the New York Stock Exchange (NYSE) and is equally weighted. While general investment logic implies sectoral diversification of portfolios, the paper focused solely on the financial sector in order to estimate its reactions. Moreover, only companies with significantly large capitalizations are used for the analysis since they are considerably more traded than stocks of small companies, impacting a larger proportion of the total market investors. A more general approach is thus left open for any further researches. An event study analysis is applied for 15 events of high significance in the USA, all of them related to the COVID-19 pandemic. Each of these events is registered as either 'good' or 'bad' with a ratio of 7 to 8, respectively. The reaction of the portfolio return performance is observed, to check for any potential event-induced abnormalities. Each effect is checked through a standard t-test for its statistical significance. General results indicate that events in the earlier stage of the pandemic exhibit both higher abnormal returns and significance, compared to the ones at the latter stages. Roughly, half of the events are significant in the study, with a tendency of them being negative rather than positive. Substantial anticipation of such events is common with mostly insignificant adjustments after the event date, indicating market efficiency in incorporating information into the prices of assets.

The rest of the paper is organized as follows. Section 2 deals with the existing relevant literature related to the topic and its empirical findings. In Sections 3 and 4 the methodological approach of the event study, as well as the research results, are presented and discussed. Finally, a brief conclusion on the topic is provided.

\section{LITERATURE REVIEW}

Portfolio theory is commonly presented alongside the efficient market hypothesis (EMH) indicating that all the available information is quickly incorporated into security prices, leaving little or no room for additional adjustments (Basu, 1977). Since event study analysis was introduced, testing for the validity of the EMH became more common in academic researches. Stock splits and their impact on return and volatility were first introduced through a market model event study (Fama, et al., 1969). In addition, Fama (1970) however, raises concern about whether a truly efficient market can be achieved. Such a null hypothesis stating a complete reflection of all disposable information seems too rigid to begin with. Theoretical and empirical proofs indicate that the presence of return abnormalities is due to specific corporate events, rather than pure coincidence. Dividing the event period into prior and post-event intervals helps detect security reactions that deviate from the expected returns, thus drawing conclusions on the overall market efficiency. Commonly, when the adjustment period after the event contains non-zero abnormal returns that do not diminish quickly is a clear sign of violating the EMH (Kothari \& Warner, 2007). Event studies are often conducted for both short and long event windows, being perceived as more powerful in detecting shocks generated by events.

Several questions arise when taking this methodological approach. Henderson (1990) notes that defining the event date is not as simple as it looks like since the market interest in the event matters higher than the news itself. If the market agents form a relevant expectation for an 
event prior to its occurrence, this may lead to choosing an insignificant announcement date. Moreover, the market structure and depth play a major role in price valuation and its relation to the impact of the event. Additionally, the event and estimation windows need to be properly determined as this methodology is highly sensitive to them. Usually, estimation and event windows are separated by a 'gap', ensuring that the model set is not influenced by the event. MacKinlay (1997) highlights this importance since estimating the benchmark model should be free of any abnormalities and unstable volatility.

Studies differ substantially in the used methodology since different problems imply various approaches in grasping the factors of interest. However, they all have one thing in common making use of the expected return models, varying between purely statistical to general market models. Dyckman et al. (1984) conduct a simulation of different methodological approaches in a daily data event study. Results show that although slightly, the market model is preferred to the mean-adjusted returns model and the market-adjusted returns model when working with a single-day event. While returns can be volatile due to specific events, their significance is not necessarily guaranteed. Empirical evidence points out the overall superiority of abnormal return standardization and using a t-test in hypothesis testing (Armitage, 1995). Our paper follows this approach in the empirical section.

Traditionally the event study literature focuses on questions such as the impact of stock splits, dividend announcements, mergers and other corporate events on stock prices. However, it is not uncommon to consider non-corporate events as important factors. Fama et al. (1969) as well as Nayak and Prabhala (2001) found that stock splits impact stock prices positively. The latter research estimates that $46 \%$ of the valuation effects are attributed to the associated dividend information following the announcements of stock splits. Davies and Studnicka (2018) found negative effects on stock prices on the early announcement of Brexit. Even the USA-China trade war has been stated throughout an event study (Egger \& Zhu, 2020). A substantial negative impact is assessed for both American and Chinese firms, as well as thirdparty firms mostly being 'collateral damage' due to global trade integrations.

The global literature quantifying the impact of the coronavirus pandemic grows at fast rates. Researchers and academicians conduct event studies not just on stock markets, but on wider financial implications to firms in almost every sector. He et al. (2020) studied the stock market in China from June 2019 to March 2020. By employing the market model the authors found evidence of the negative impact of the pandemic in the labor-intensive sectors, while the IT industry, education and health sectors reacted positively. Similar conclusions can be drawn by Yan and Qian (2020) for the consumer sector. However, the adverse effects last shortly, mostly due to the quick reactions of Chinese authorities. Alam et al. (2020) studied the lockdown announcement effects for the case of the Indian stock market, which arguably reacted positively. The authors account such movements to the positive expectations of a better public health situation, leading the investors to 'buy the dip'. A rather interesting point is highlighted by Heyden and Heyden (2021). They note that while the US and European stocks do not react significantly to the first registered coronavirus case, they do on the news of the first registered death. Moreover, transparent reactions of central banking institutions helped in calming the markets more than the fiscal authorities.

We focus solely on the financial sector for stocks traded at the NYSE. Our firm belief is that this industry is a relevant indicator of overall economic conditions and reactions, due to its high integration with all economic sectors. While the literature mainly focuses on comparing industries, health-related events and deals with events in the first five months of 2020, we note and quantify the significance of different types of news throughout the whole year. This study serves as a necessary fill-in the pre-existing literature gap on the impact of the pandemic. 


\section{HYPOTHESES AND RESEARCH METHODOLOGY}

This paper deals with the persistent question of whether SARS-CoV-2 related news is a significant source of abnormalities in stock prices. A total sample of 1259 daily observations (only trading days included) is analyzed to check whether the null hypothesis of zero abnormal returns can be rejected for a specific event. We focus on 15 events, out of which 8 are classified as bad ones. Primary data were obtained from the New York Stock Exchange database from 2016 through 2020. The databases of NASDAQ and Yahoo Finance are used as a potential backup in obtaining the necessary data, as well as for the information on different corporations. Data on the 3-month US Treasury Bill as a risk-free rate of return is obtained from the Board of Governors of the Federal Reserve System. The event study analysis deals with the return reactions of a provisional 'purely financial' portfolio consisting of 20 corporations classified with market capitalization varying between $\$ 300 \mathrm{M}$ and over $\$ 200 \mathrm{~B}$, all listed for trading on the New York Stock Exchange. According to the classification provided at NASDAQ, we focus on small, medium, large and mega capitalizations of companies. Micro and nano capitalizations are not of interest in this study. The randomization process of the portfolio is done similarly to the process of a stratification sampling, with random 10 companies chosen from the $\$ 10 \mathrm{~B}-$ over $\$ 200 \mathrm{~B}$ capitalization sample, and an additional 10 from the $\$ 300 \mathrm{M}-\$ 10 \mathrm{~B}$ intervals. To keep the study unbiased and completely randomized, we decide not to disclose information about the stocks incorporated in the study portfolio. The returns of the S\&P500 index are used as the market return component in further modeling.

\subsection{Empirical background of the event study}

Event studies of stock market reactions are based on returns and their potential abnormalities i.e. deviations from the expectations. We begin off with calculating the individual stock returns as:

$$
r_{i t}=\frac{p_{t}-p_{t-1}}{p_{t-1}} * 100
$$

The aggregate portfolio return is a simple average, having in mind the proposed equal weights of each stock included:

$$
R_{t}=\frac{1}{N} * \sum_{i=1}^{N} \sum_{t=0}^{T} r_{i t}
$$

The notations $r_{i t}$ and $R_{t}$ indicate the rates of return of an individual stock and the portfolio, respectively, $p$ is the price of a given stock, with $i=1,2,3, \ldots, N$ as a stock notation in the period $t=1,2,3, \ldots, T$. However, due to the specific nature of the analysis, we are interested only in the abnormal returns. Such terminology is used for the proportion of the return differing from its expected return. The following relationship consisting of expected i.e. observed and unobserved components is present:

$$
R_{t}=E\left(R_{t}\right)+\epsilon_{t}
$$

The expected return is a component that comes naturally, depending on a pre-specified model of the relationship between the share itself and perhaps the overall market. The error term is responsible for the abnormalities in price movements, creating a return conditional to a set of public and insider information $R_{t}=\left[r_{t} \mid \Omega_{t}\right]$. Abnormal returns are consequently the difference term:

$$
A R_{t}=R_{t}-E\left(R_{t}\right)
$$

The literature proposes a vast number of approaches in modeling the expected return of a single stock, or even a portfolio. The constant mean return treats the average rate of return in the estimation window as the expected rate, while the market model includes the interaction 
between a stock's performance and the overall market. Three-factor models can also be employed, as well as linear regressions but in this research, the Capital Asset Pricing Model is taken as the fundament for obtaining the expected returns of each stock of interest in our portfolio. The following equation deals with this problem:

$$
E\left(R_{i t}\right)=R_{f, t}+\beta_{i}\left(R_{m, t}-R_{f, t}\right)
$$

The expected return of a stock is calculated with the likes of the market risk premium $\left(R_{m, t}\right.$ $\left.R_{f, t}\right)$, the risk-free rate of return which in our case it's the 3-month US Treasury bill and the stock's beta parameter, measuring the volatility relative to the overall market. It can be obtained through simple OLS regression, where the dependent variable is the respective stock, while a given market index (in our case the S\&P500) is the independent variable.

Figure 1: Event study timeline

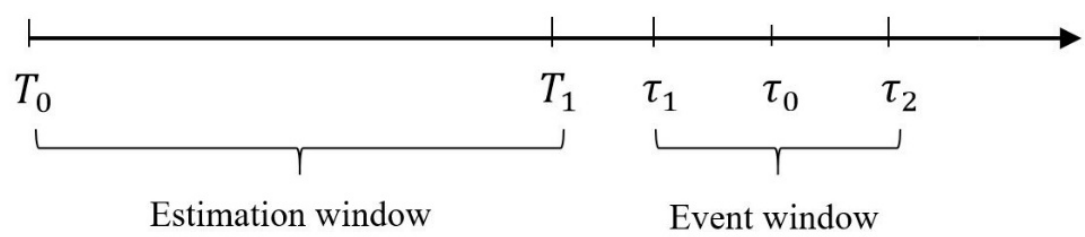

(Source: Authors'work)

As testing for portfolio reactions to specific events makes little sense to be analyzed on daily basis around the event date, cumulative abnormal returns (CAR) are thus calculated. With them, we can observe the cumulative effect in an event window segregated into four different segments: anticipation, event, adjustment and total event window. The cumulative abnormal returns are adequate for short-term analysis rather than their BHAR (buy and hold abnormal returns) counterpart which is more suitable for longer event windows. CARs are calculated as:

$$
\operatorname{CAR}_{\left(\tau, \tau^{\prime}\right)}=\sum_{i=\tau}^{\tau^{\prime}} A R_{i} \forall \tau, \tau^{\prime} \in N
$$

For this specific research for all 15 events of interest, a [-10, 5] event window is used, except for the first event which studies the $[-5,5]$ window in order not to overlap the estimation and the event periods. As generated results can be biased in direct interpretation, a standardized Student's t-test is employed when checking the statistical significance of the estimates. The standard deviation of the abnormal returns is calculated based on the estimation window ranging $T_{0}$ to $T_{1}$, to further reject the null hypotheses stated as statistical equalization to zero of the abnormal returns:

$$
\begin{gathered}
H_{0}: A R_{t}=0 \\
H_{1}: A R_{t} \neq 0 \\
H_{0}: C A R_{\tau, \tau^{\prime}}=0 \\
H_{1}: C A R_{\tau, \tau^{\prime}} \neq 0
\end{gathered}
$$

The test statistics for the significance of the abnormal returns on the event day $\tau_{0}$ are consequently calculated in the following principle according to Khotari and Warner (2007):

$$
S A R_{\tau_{0}}=\frac{A R_{\tau_{0}}}{\sigma_{A R}}
$$

While the significance of a particular sub-event window as:

$$
\operatorname{SCAR}_{\left(\tau, \tau^{\prime}\right)}=\frac{C A R_{(t, \tau)}}{\sqrt{\left|\left(\tau-\tau^{\prime}+1\right)\right|} \sigma_{A R}}
$$

With $\tau$ and $\tau^{\prime}$ indicating the lower and the upper bound of the interval of interest. 


\section{RESULTS AND DISCUSSION}

Before the creation of the standardized event study table, we need to carefully study the overall changes in our portfolio to get prior knowledge where possible abnormalities are concentrated throughout 2020. Table 2 shows the portfolio return heat map for the entire sample period from 2016 to 2020 , by transforming daily returns into monthly by simply averaging them. In 2020 there are evident outliers in the first quarter, and partly in the second and fourth, implying that the most significant COVID-19 related news should perhaps be concentrated there.

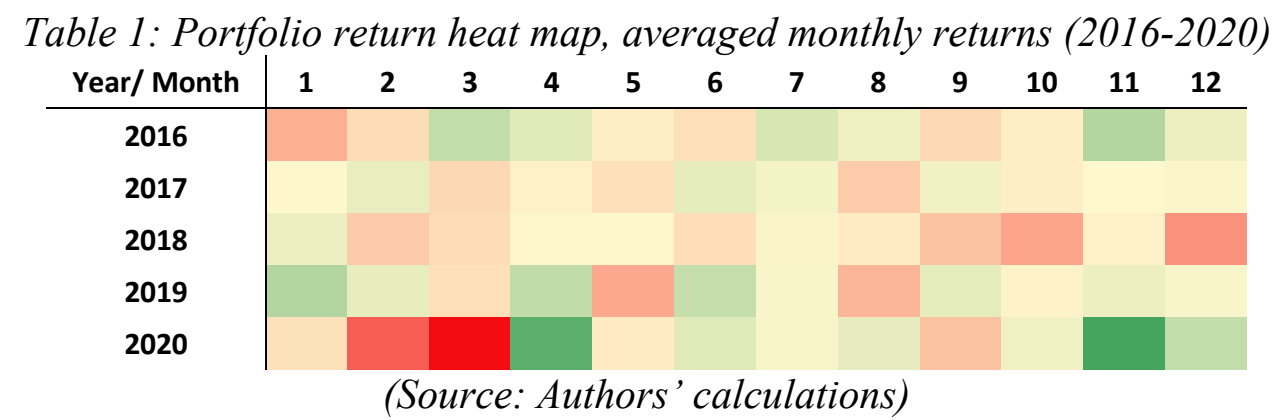

The line graph of portfolio returns also confirms the increased volatility in 2020, which makes the chosen estimation window of 2016-2019 justified. Returns vary between $8.71 \%$ and $15.63 \%$ with a standard deviation of $1.46 \%$. Descriptive statistics indicate that the distribution is non-normal and leptokurtic, which is expected for financial data series.

Figure 2: Daily portfolio returns (2016-2020)

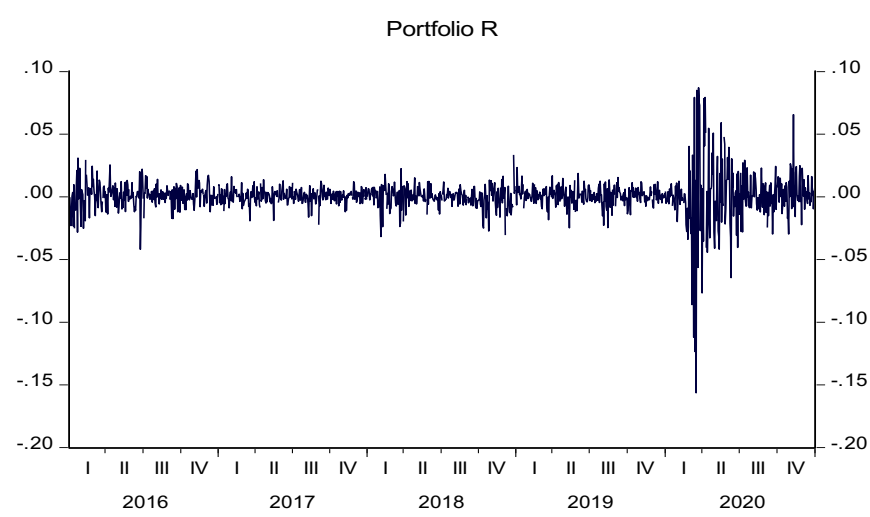

(Source: Authors' calculations)

In the process of event analysis, we ought to analyze the cumulative abnormal returns of our 20 -stock financial portfolio for each event date. Figures 3 to 6 illustrate this category. Most of the CARs follow a general tendency in the event window, with the event itself creating an additional positive or negative reaction to the returns. There is no clear signal of a shift in abnormal returns, meaning that on average CARs for pre and post-event windows remain with the same sign. However, quantifying the abnormal returns goes alongside testing for their significance as previously stated. Specific events and their dates of announcements are given in detail in Table 2, alongside the estimates of the event study. 

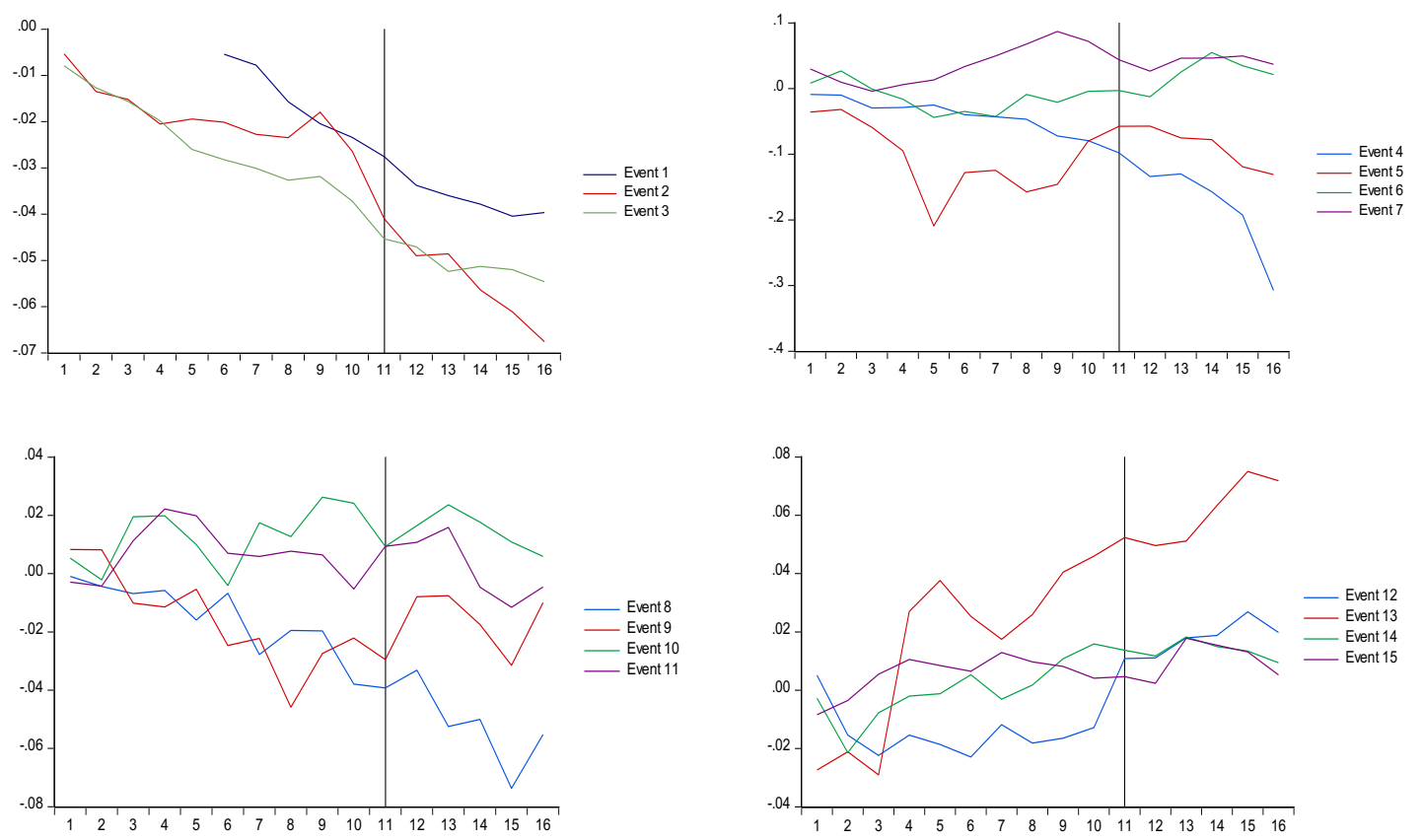

(Source: Authors'calculations)

A little to no impact had the announcement of the World Health Organization about detecting a new type of coronavirus in Southern China, as then almost no attention was given to the potential hazard that followed. Significant and negative CAR for the anticipation window is estimated at $-2.34 \%$ at the $5 \%$ level. We believe that this might account for possible insider trading or investment decisions unrelated to the topic of this paper, with the latter being more likely the case.

Even though a significance at the $10 \%$ level, the estimated abnormal return of the second event (first US COVID case) is $-0.815 \%$ showing that the market reacted negatively. Moreover, the cumulative abnormal return for the prior 10-day window is significant at $5 \%$ signaling that investors anticipated such an event. The global spread of coronavirus was a matter of time before reaching the USA and such an event seemed logical and imminent to happen.

On February 3, 2020, the USA declared a national health emergency with the number of cases steadily growing and due to the Chinese experience with the virus at that point. The adverse reaction of the financial sector was accompanied by both significant anticipation and adjustment windows. The presence of non-zero and significant abnormal returns in the postevent timeline of 5 days signals a violation of the EMH. The information did not incorporate completely into the prices of the proposed portfolio with the occurrence of the event. Investor decisions signal that the event itself did not value the assets appropriately and a further downward correction was expected.

Once the WHO declared the SARS-CoV-2 virus a global pandemic, markets started to crumble. The announcement devalued the financial portfolio by roughly $2 \%$ more than its expected value at that point. The event window for March $11^{\text {th }}$ shows significance at $1 \%$ for each sub-interval. This large drop in the stock prices before the event date was expected since the global spread showed signs of a pandemic weeks before. Investors reacted accordingly and signaled a further plummeting. However, highly interesting is the post-event adjustment period. In just five days after the event the financial sector companies loss almost $21 \%$ relative to the expectation. This confirms an inefficient market at the point in incorporating all disposable public and historical information in the prices of the assets and a clear undervaluation of the event itself in the prior 
period. Moreover, a large proportion of investor decisions can be accounted for purely behavioral factors. Small investors usually follow large investor decisions in such events and are prone to decisions based on the general perspective of an occurrence. Expectations of worsened economic conditions at that point grew exponentially, justifying the investors' reactions.

Up until the end of March, no potentially good news came out in public. The introduction of the CARES act of the US government proved otherwise. Amounting \$2.2 trillion it was introduced as a national economic stimulus in fighting the rapid drop in economic activity and everyday growth of unemployment. This event proved to be especially significant and created a positive environment for re-investment and economic recovery. As the financial sector depend ultimately on the condition and performance of the real sector and financial power of the households, the growth in abnormal returns on the event date is expected since it is positive news. However, both anticipation and adjustment periods defy the theoretical expectations. As the CARs are negative for the adjustment period they imply market overreaction on the given news. The worsening health environment and overall skepticism for going back to normal played their part. While most firms and businesses operated at the margins of rentability, no signs of the soon-to-come lifting of restrictions did their own thing in ensuring negative returns. Nevertheless, it is worth noting that positive market movements happened in the following period. This leads us to a conclusion that perhaps the especially short post-event window is the reason why good news such as passing the CARES act led to negative adjustments afterward. An interesting phenomenon is observed in the set of vaccine-related events. None of them appears to be significant besides the news that Moderna entered Phase 3 in clinical trials parallel with reaching a deal with the US Government of its future distribution and the announcement of the National vaccine distribution plan. The prior event led to significant and negative abnormal returns. Even though it defies common logic, a general skepticism of the pace and efficacy in vaccine development probably is the main cause for such a result. The financial sector portfolio however steadily regained positive momentum afterward, generating a $1.5 \%$ abnormal return on the latter event, statistically significant at $1 \%$.

The financial sector stocks did not experience substantial negative returns when announcing that the US President and the First Lady were infected with the coronavirus. Moreover, we must note that the overall insignificance in events that followed in the second half of 2020 may be due to the following reasons. Firstly the estimation window ends on December 31, 2019, and thus a substantially large gap exists between the estimation and event windows. Even though this was deliberately done to prevent drastic changes in the estimated CAPM model which should have incorporated the large fluctuations in the first quarter of 2020, we are aware of the restriction that it may pose to the analysis. Additionally, as health experts and society understood the nature of the virus more, investor reactions became less drastic and markets eventually started to return to the pre-pandemic levels. The financial sector regained momentum and investor confidence substantially grew. The overall event study proved that markets have adjusted inefficiently in the moment of big events of non-corporate character. The efficient market hypothesis was violated in the case of the financial sector portfolio during the beginning of the pandemic, with investors mostly anticipating and reacting accordingly to later events. 
Table 2: Cumulative abnormal returns of the research portfolio by events, 2020

\begin{tabular}{|c|c|c|c|c|c|}
\hline Date & Event & News & CAR & $\mathrm{n} \%)$ & t-stat. \\
\hline & & & Event & -0.420 & -0.864 \\
\hline January 9 , & WHO officially detects coronavirus pneumonia & & Anticipation & $-2.338^{* *}$ & -2.152 \\
\hline 2020 & {$[-5,5]$} & Bad & Adjustment & -1.205 & -1.109 \\
\hline & & & Total & $-3.963^{* * *}$ & -2.459 \\
\hline & & & Event & $-0.815^{*}$ & -1.678 \\
\hline January 21 , & First US case and confirmed human transmission & & Anticipation & $-3.719^{* *}$ & -2.420 \\
\hline 2020 & {$[-10,5]$} & Bad & Adjustment & -0.927 & -0.853 \\
\hline & & & Total & $-5.461^{* * *}$ & -2.809 \\
\hline & & & Event & $-1.460^{* * *}$ & -3.004 \\
\hline February 3 , & US public health emergency & Rad & Anticipation & $-2.639^{*}$ & -1.718 \\
\hline 2020 & {$[-10,5]$} & ваa & Adjustment & $-0.532^{* *}$ & -2.447 \\
\hline & & & Total & $-6.757^{* * *}$ & -3.476 \\
\hline & & & Event & $-1.862^{* * *}$ & -3.832 \\
\hline March 11, & WHO declares COVID-19 a pandemic & & Anticipation & $-7.941^{* * *}$ & -5.168 \\
\hline 2020 & {$[-10,5]$} & $B a d$ & Adjustment & $-20.928^{* * *}$ & -19.260 \\
\hline & & & Total & $-30.731^{* * *}$ & -15.810 \\
\hline & & & Event & $2.272^{* * *}$ & 4.676 \\
\hline March 26, & The Senate passes the CARES act & & Anticipation & $-8.010^{* * *}$ & -5.212 \\
\hline 2021 & {$[-10,5]$} & Good & Adjustment & $-7.370^{* * *}$ & -6.783 \\
\hline & & & Total & $-13.108^{* * *}$ & -6.744 \\
\hline & & & Event & 0.116 & 0.238 \\
\hline May 21, & The US Government and AstraZeneca vaccine deal & & Anticipation & -0.427 & -0.278 \\
\hline 2020 & {$[-10,5]$} & Good & Adjustment & $2.438^{* *}$ & 2.243 \\
\hline & & & Total & 2.126 & 1.094 \\
\hline & & & Event & $-2.828^{* * *}$ & -5.820 \\
\hline June 10 , & USA surpasses 2 million coronavirus cases & & Anticipation & $7.196^{* * *}$ & 4.683 \\
\hline 2020 & {$[-10,5]$} & Bad & Adjustment & -0.668 & -0.615 \\
\hline & & & Total & $3.700^{*}$ & 1.904 \\
\hline & & & Event & -0.131 & -0.270 \\
\hline July 2 , & Delayed 'reopening' of the economy & & Anticipation & $-3.793^{* *}$ & -2.468 \\
\hline 2020 & {$[-10,5]$} & Ваd & Adjustment & -1.601 & -1.473 \\
\hline & & & Total & $-5.525^{* * *}$ & -2.842 \\
\hline & & & Event & -0.743 & -1.529 \\
\hline July 14, & Moderna vaccine - good signs of efficacy in early trial & & Anticipation & -2.221 & -1.439 \\
\hline 2020 & {$[-10,5]$} & Good & Adjustment & $1.959^{*}$ & 1.803 \\
\hline & & & Total & -0.995 & -0.512 \\
\hline & & & Event & $-1.480^{* * *}$ & -3.046 \\
\hline July 27, & Moderna enters phase $3-$ a $\$ 472 \mathrm{M}$ deal with the US & Good & Anticipation & 2.414 & 1.571 \\
\hline 2020 & $\begin{array}{l}\text { Government } \\
{[-10,5]}\end{array}$ & Good & Adjustment & -0.343 & -0.315 \\
\hline & & & Total & 0.591 & 0.304 \\
\hline & & & Event & $1.468^{* * *}$ & 3.021 \\
\hline September & National vaccine distribution plan & & Anticipation & -0.528 & -0.344 \\
\hline 16,2020 & {$[-10,5]$} & Good & Adjustment & $-1.399^{* *}$ & -1.288 \\
\hline & & & Total & $-0.460^{*}$ & -0.236 \\
\hline & & & Event & $1.468^{* * *}$ & 4.872 \\
\hline October 2 & President Trump and the First Lady tested positive - & & Anticipation & -1.280 & -0.833 \\
\hline 2020 & Trump immediate hospitalization & Bad & Adjustment & 0.892 & 0.821 \\
\hline & & & Total & 1.979 & 1.018 \\
\hline & & & Event & 0.642 & 1.320 \\
\hline November & Pfizer vaccine $95 \%$ efficacy & Good & Anticipation & $4.596^{* * *}$ & 2.991 \\
\hline 18,2020 & {$[-10,5]$} & Good & Adjustment & $1.948^{*}$ & 1.793 \\
\hline & & & Total & $7.186^{* * *}$ & 3.697 \\
\hline & & & Event & -0.210 & -0.432 \\
\hline December & FDA approves shipments of the Pfizer vaccine & Good & Anticipation & 1.583 & 1.030 \\
\hline 11,2020 & {$[-10,5]$} & Good & Adjustment & -0.432 & -0.397 \\
\hline & & & Total & 0.941 & 0.484 \\
\hline & & & Event & 0.051 & 0.105 \\
\hline December & New highly infectious 'alpha' strain discovered (UK & & Anticipation & 0.413 & 0.268 \\
\hline 21,2020 & $\begin{array}{l}\text { variant) } \\
{[-10,5]}\end{array}$ & Bad & Adjustment & 0.058 & 0.053 \\
\hline & {$[-10,3]$} & & Total & 0.521 & 0.268 \\
\hline
\end{tabular}

${ }^{* * * * * * *}$ indicate $.01, .05$ and .1 statistical significance, respectively.

(Source: Authors' calculations) 


\section{CONCLUSION}

The event study analysis proves to be of immense importance in determining significance in market and portfolio reactions to events. As the COVID-19 pandemic made security investment turbulent, assessing its effect was necessary.

A random sample of financial sector stocks was used to create a portfolio upon which we test for the presence of abnormalities in its returns, given a set of 15 events. The news distribution is almost equal with 8 bad and 7 good news related to the US case of the pandemic. General results indicate that the highest significance of events is estimated in the first quarter of the year. The possibility of insider trading prior to announcements is possible and yet unlikely. In periods of the high volatility of prices, adjustment period significance indicates a violation of the semi-strong efficient market hypothesis. The event reaction in bad news was mostly undervalued leading to a further downward correction of prices. Vaccine-related news are estimated as insignificant, defying our hypotheses and expectations before the research.

While the study focuses only on the financial sector, due to its high integration with all sectors in the economy a general conclusion can be drawn that the COVID-19 related events significantly distorted market conditions.

\section{REFERENCES}

Alam, M. N., Alam, M. S. \& Chavali, K., 2020. Stock Market Response during COVID-19 Lockdown Period in India: An Event Study. Journal of Asian Finance, Economics and Business, 7(7), pp. 131-137.

Armitage, S., 1995. Event Study Methods and Evidence on Their Performace. Journal of Economic Surveys, 9(1), pp. 25-52.

Basu, S., 1977. Investment Performance of Common Stocks in Relation to Their PriceEarnings Ratios: A Test of the Efficient Market Hypothesis. The Journal of Finance, 32(3), pp. 663-682.

Davies, R. B. \& Studnicka, Z., 2018. The heterogeneous impact of Brexit: Early indications from the FTSE. European Economic Review, Volume 110, pp. 1-17.

Dyckman, T., Philbrick, D. \& Stephan, J., 1984. A Comparison of Event Study Methodologies Using Daily Stock Returns: A Simulation Approach. Journal of Accounting Research, Volume 22, pp. 1-30.

Egger, P. H. \& Zhu, J., 2020. The U.S.-China Trade War: An Event Study of Stock-Market Responses. Economic Policy, 35(103), pp. 519-559.

Fama, E., 1970. Efficient Capital Markets: A Review of Theory and Empirical Work. The Journal of Finance, 25(2), pp. 383-417.

Fama, E. F., Fisher, L., Jensen, M. C. \& Roll, R., 1969. The Adjustment of Stock Prices to New Information. International Economic Review, 10(1), pp. 1-21.

Henderson, G. V., 1990. Problems and Solutions in Conducting Event Studies. The Journal of Risk and Insurance, 57(2), pp. 282-306.

He, P., Sun, Y., Zhang, Y. \& Li, T., 2020. COVID-19's Impact on Stock Prices Across Different Sectors - An Event Study Based on the Chinese Stock Market. Emerging Markets Finance and Trade, 56(10), pp. 2198-2212.

Heyden, K. J. \& Heyden, T., 2021. Market reactions to the arrival and containment of COVID19: An event study. Finance Research Letters, Volume 38, p. 101745.

Kothari, S. P. \& Warner, J. B., 2007. Econometrics of Event Studies. In: B. Espen Eckbo, ed. Handbook of Corporate Finance. Amsterdam: North-Holland, Elsevier, pp. 3-36.

MacKinlay, C. A., 1997. Event studies in economics and finance. Journal of Economic Literature, 35(1), pp. 13-39. 
Nayak, S. \& Prabhala, N. R., 2001. Disentangling the Dividend Information in Splits: A Decomposition Using Conditional Event-Study Methods. The Review of Financial Studies, 14(4), pp. 1083-1116.

Yan, L. \& Qian, Y., 2020. The Impact of COVID-19 on the Chinese Stock Market: An Event Study Based on the Consumer Industry. Asian Economics Letters, 1(3), pp. 1-5. 